\title{
Preference Learning in Consecutive Experimental Auctions
}

\author{
Jason F. Shogren, John A. List, and Dermot J. Hayes
}

\begin{abstract}
This paper explores the origins of the strikingly high price premia paid for new food products in lab valuation exercises. Our experimental design distinguishes between two explanations of this phenomenon: novelty of the experimental experience versus the novelty of the good, i.e., preference learning - bids reflect a person's desire to learn how an unfamiliar good fits into their preference set. Subjects bid in four consecutive experimental auctions for three goods that vary in familiarity, candy bars, mangos, and irradiated meat. Our results suggest that preference learning is the main source of the high premia, and that novelty of the experimental experience does not in itself artificially inflate valuations.
\end{abstract}

Key words: experimental auctions, preference learning, price premia.

Laboratory valuation auctions have emerged as a serviceable tool to elicit a person's actual willingness to pay for new products such as growth hormone milk and beef, irradiated meat, pesticide-free fruit, and food safety. ${ }^{1}$ The evidence from these auctions suggests that the average person is willing to pay a price premium for many new products. But some observers have pointed out that this premium often exceeds expectations of what they think people would actually pay in a real retail market. In the case of food safety, for instance, the average person was willing to pay a one-time 70 cent per meal price premium to reduce the health risk from foodborne pathogens - a premium that some observers familiar with the market for safer food believe to be unduly high (Hayes et al.). ${ }^{2}$

The open question is why price premia might be so high in the lab. One explanation

\footnotetext{
Shogren is the Stroock Distinguished Professor of Natural Resource Conservation and Management, Department of Economics and Finance, University of Wyoming, Laramie, WY 82071-3985; List is assistant professor, Department of Economics, University of Central Florida, Orlando, FL 32765; Hayes is the Pioneer Hi-Bred professor of Agribusiness, Department of Economics, Iowa State University, Ames, IA 50011.

The authors acknowledge the financial support of the Food Safety Consortium and NSF grant \#0SBR94-22813. Robert Wilhelmi provided valuable research assistance. Peter Frykblom and two reviewers supplied helpful comments.

${ }^{1}$ See for example Hoffman et al., Fox et al. (1994, 1995, 1998), and Roosen et al.

${ }^{2}$ This $\$ 0.70$ premium would translate into national food safety benefits at least three times greater than any current estimate. The implied value of risk to life would be over $\$ 70$ million, an order of magnitude greater than standard estimates (see Viscusi).
}

might be the novelty of the experimental experience. ${ }^{3}$ The auctions have thus far been designed as a one-time experience in which a person submits bids in multiple trials in one treatment on one day. The fear is that bidders in a one-afternoon auction might experiment with their bids, bidding high because the costs of doing so are low. Some bidders might be able to afford a high price premium in a new and singular setting.

Theory suggests an alternative explanation for the high price premia - the novelty of the good. Many bidders have never experienced the goods up for auction, e.g., irradiated meat. In this case, theory says that a bid will reflect two elements of value - the consumption value of the good and the information value of learning how the good fits into his or her preference set (Grossman, Kihlstrom, and Mirman; Crocker and Shogren). Preference learning would exist if people bid large amounts for a good because they wanted to learn about an unfamiliar good they had not previously consumed, it was unique, or because it was unavailable in local stores.

Herein we use the lab to test between these two explanations by auctioning off three goods that vary in familiarity-candy bars, mangos, and irradiated pork. Subjects bid in four consecutive experimental auctions over two-weeks. And if experimental-novelty tells

\footnotetext{
${ }^{3}$ Other robustness tests have shown that bidding behavior in lab valuation exercises is sensitive to the auction mechanism, price signals, and non-price information (see for example Rutström).
} 
the story, we should expect to see average bids dropping as the novelty wears off for all three goods, familiar or unfamiliar. But if preference learning organizes bidding behavior, average bids should remain relatively stable for the familiar goods and should decline for unfamiliar goods once people become familiar with the novel good. Our results suggest that preference learning is a main source of the high price premia. We measure no statistical change in bids for candy bars and mangos, whereas the price premia for irradiated pork dropped by $50 \%$ over the four sessions. These findings suggest that the novelty of the lab adventure in itself does not artificially inflate bids. Bidding behavior is consistent with the view that people bid above their standard consumption value because they value experience. They benefit from the information they gather about how an unfamiliar good fits into their preference ordering.

\section{Experimental Design and Hypotheses}

Our experimental design follows Hayes et al.'s lab auctions as close as possible. Monitors recruited two groups of fifteen subjects each from the student body at Iowa State University (ISU). Each group was scheduled to attend four sessions over a twoweek period. Subjects were paid $\$ 10$ for each session, and to encourage perfect attendance, after session number four a $\$ 50$ bonus was paid to subjects who attended all four sessions. We ran all sessions in a taste-testing room at the ISU Meat Laboratory.

Each session had three stages, identical except for the endowed and auctioned goods. ${ }^{4}$ In stage one, the monitor endowed each subject with a brand name candy bar. Each subject submitted a sealed bid revealing the amount he or she would be willing to pay to exchange their candy bar for an alternative brand of candy bar. All auctions used a sealed bid, second-price auction repeated over five trials (Vickrey). ${ }^{5}$ After collecting bidding cards, the monitors publicly displayed the identification number of the highest bidder and the second highest bid (i.e., market price) on the blackboard. After trial five,

\footnotetext{
${ }^{4}$ At the beginning of session one, the monitor ran a training auction for packs of gum so subjects could learn about the second-price auction mechanism.

${ }^{5}$ Since we are interested in the phenomenon of lab valuation within repeated markets, the auction was repeated over five trials to allow participants to gain experience.
}

the monitor randomly selected one of the five trials as the binding trial. ${ }^{6}$ The highest bidder in the binding trial exchanged his or her candy bar for the alternative and paid the market price; all other bidders kept their initial endowments.

In stage two, we ran the food safety auctions. The monitors displayed two types of pork meat purchased from a local food store. The only difference between the two types was that one had been treated with irradiation at the linear accelerator facility on the ISU campus to control for Trichinella (see Fox et al., 1998). The monitors informed the subjects that they now owned a sandwich made from the non-irradiated pork, and then provided information on the likelihood and severity of Trichinella and the irradiation process. Each subject then submitted a sealedbid stating his or her willingness to pay to exchange the non-irradiated pork sandwich for the irradiated pork sandwich. Again, one of the five trials was the binding trial. Subjects were fully aware that to exit with their take-home income they needed to eat their sandwich at the end of the session.

In stage three, all procedures where identical except that each subject was endowed with an apple and asked to reveal his or her willingness to pay to exchange the apple for a mango. The subjects repeated the three stages during each of the four sessions such that each person submitted fifteen bids per stage, sixty bids total.

Our experimental design allows us to investigate the origins of the high price premia through two paths. First, we explore whether the novelty of the experimental experience or the novelty of the good is the source of the high price premia. If the experimental novelty explains behavior, average bids should decline for all three goods. Alternatively, if novelty of the good organizes behavior, bids should remain relatively constant for candy and mangos, and decline for irradiated pork. Our null experimental novelty hypothesis is that consecutive auctions will not result in declining values for any of the three products, candy bar, mangos, and the new food safety process.

Second, we explore the good-novelty and preference learning idea in more depth by considering the behavior of the winning bidders who actually experienced the unfamiliar good in at least one session. The theory

\footnotetext{
${ }^{6}$ This randomization design controls for wealth effects.
} 
of preference learning posits that (a) a person's willingness to pay for the unfamiliar good will be weakly greater than when he has better preference knowledge, and (b) his willingness to pay will be non-increasing with experience (Crocker and Shogren). Preference learning suggests that a person will bid more than his consumption value to gain information on how the unfamiliar good fits into his preference ordering. Once he gains sufficient information by actually eating the good, his bid will approach his consumption value from above (see the preference learning model in the appendix, which is available from the authors on request). Our null preference learning hypothesis is that the winning bidder will not decrease his or her bid after winning the good in the previous session. Rejecting this null supports the idea of preference learning.

\section{Results and Discussion}

We present our results in two partsunconditional and conditional. The unconditional results reveal the pattern of bidding behavior without controlling for factors that could affect the level of bids. The conditional results account for individual and timespecific effects, and posted price and "winner" effects.

\section{Unconditional Means Differ Across Sessions, but Only for Unfamiliar Goods}

Table 1 summarizes our experimental data. The top panel presents the mean and variance of the overall bids in each of the three categories. We cannot reject the experimental novelty null hypothesis for the candy bar and the mango, but we do reject the null for the irradiated pork. This leads us to conclude that novelty of the experimental experience is not enough to inflate bids artificially.

To see this in more detail, consider first average bidding in the candy bar auctions. An interesting trend in these data is that for the most familiar good-candy-the mean bid fluctuates little, ranging between one and a half and two cents. Using a paired difference $t$-tests, the results suggest that individual bids in the candy auctions were not significantly different across the four sessions

Table 1. Summary Statistics

\begin{tabular}{|c|c|c|c|}
\hline & Candy & Mango & Pork \\
\hline \multicolumn{4}{|c|}{ Overall Mean Bid } \\
\hline Session 1 & $\begin{array}{l}\$ 0.019 \\
(0.002)\end{array}$ & $\begin{array}{l}\$ 0.036 \\
(0.005)\end{array}$ & $\begin{array}{l}\$ 0.125 \\
(0.02)\end{array}$ \\
\hline Session 2 & $\begin{array}{l}\$ 0.020 \\
(0.001)\end{array}$ & $\begin{array}{l}\$ 0.050 \\
(0.010)\end{array}$ & $\begin{array}{l}\$ 0.095 \\
(0.015)\end{array}$ \\
\hline Session 3 & $\begin{array}{l}\$ 0.022 \\
(0.003)\end{array}$ & $\begin{array}{l}\$ 0.055 \\
(0.013)\end{array}$ & $\begin{array}{l}\$ 0.078 \\
(0.018)\end{array}$ \\
\hline Session 4 & $\begin{array}{c}\$ 0.016 \\
(0.001)\end{array}$ & $\begin{array}{l}\$ 0.018 \\
(0.002)\end{array}$ & $\begin{array}{l}\$ 0.062 \\
(0.0126)\end{array}$ \\
\hline \multicolumn{4}{|c|}{ Non-Winners' Mean Bid } \\
\hline Session 1 & $\begin{array}{c}\$ 0.019 \\
(0.002)\end{array}$ & $\begin{array}{l}\$ 0.036 \\
(0.005)\end{array}$ & $\begin{array}{l}\$ 0.125 \\
(0.02)\end{array}$ \\
\hline Session 2 & $\begin{array}{l}\$ 0.020 \\
(0.001)\end{array}$ & $\begin{array}{l}\$ 0.050 \\
(0.011)\end{array}$ & $\begin{array}{l}\$ 0.100 \\
(0.016)\end{array}$ \\
\hline Session 3 & $\begin{array}{l}\$ 0.026 \\
(0.003)\end{array}$ & $\begin{array}{l}\$ 0.061 \\
(0.014)\end{array}$ & $\begin{array}{l}\$ 0.073 \\
(0.017)\end{array}$ \\
\hline Session 4 & $\begin{array}{l}\$ 0.016 \\
(0.001)\end{array}$ & $\begin{array}{l}\$ 0.020 \\
(0.002)\end{array}$ & $\begin{array}{l}\$ 0.053 \\
(0.0107)\end{array}$ \\
\hline \multicolumn{4}{|c|}{ Winners' Mean Bids } \\
\hline Before Win & $\begin{array}{l}\$ 0.058 \\
(0.0046)\end{array}$ & $\begin{array}{l}\$ 0.176 \\
(0.018)\end{array}$ & $\begin{array}{l}\$ 0.225 \\
(0.034)\end{array}$ \\
\hline After Win & $\begin{array}{l}\$ 0.008 \\
(0.0006)\end{array}$ & $\begin{array}{l}\$ 0.014 \\
(0.001)\end{array}$ & $\begin{array}{l}\$ 0.088 \\
(0.019)\end{array}$ \\
\hline
\end{tabular}


(session one vs. session two: $t=-0.11 ; 1$ vs. 3 ; $t=-0.52 ; 1$ vs. $4: t=0.58 ; 2$ vs. $3: t=-0.39$; 2 vs. $4: t=0.86 ; 3$ vs. $4: t=0.97)$. Examining only the non-winner's bids in panel 2 of table 2, we find qualitatively similar results (session one vs. session two: $t=-0.29 ; 1$ vs. 3 : $t=-0.88 ; 1$ vs. $4: t=0.24 ; 2$ vs. $3: t=-0.57$; 2 vs. $4: t=0.04 ; 3$ vs. $4: t=0.53)$.

Mean bids for the mango exhibit a different trend as they increase from sessions one to three, and then decrease markedly in session four. But the bids remain statistically equivalent across most of the trials at conventional significance levels (session one vs. session two: $t=-1.07 ; 1$ vs. $3: t=-0.94 ; 1$ vs. 4 : $t=1.18 ; 2$ vs. $3: t=-0.31 ; 2$ vs. $4: t=1.94 ; 3$ vs. $4: t=2.16)$. The sole exception is between trials three and four, in which we observe a significant decrease in bid levels. As we see from paired difference $t$-tests, these results are generally consistent for non-winners' bidding data presented in panel 2 of table 1 (session one vs. session two: $t=-1.44 ; 1$ vs. 3: $t=-1.88 ; 1$ vs. $4: t=0.14 ; 2$ vs. $3: t=-1.66$; 2 vs. $4: t=1.04 ; 3$ vs. $4: t=1.74)$.

Mean bids for the more exotic good behave differently. In the irradiated pork auctions, we initially observe relatively large mean bids in session one, about 12 cents but by session four mean bids dropped in half to 6.2 cents. When comparing these means using a paired difference $t$-test we find that first, second, and third session bids are significantly less than bids in session four at the $p<.02$ confidence level (session one vs. session two: $t=1.62 ; 1$ vs. $3: t=1.94 ; 1$ vs. $4: t=3.20 ; 2$ vs. $3: t=0.51 ; 2$ vs. $4: t=2.51 ; 3$ vs. $4: t=2.99$ ). This result is broadly consistent with our findings using data for non-winners. In this subgroup, bidders in later sessions continue to shade their bids in comparison to early bids (session one vs. session two: $t=0.66 ; 1$ vs. 3 : $t=2.42 ; 1$ vs. $4: t=1.95 ; 2$ vs. $3: t=1.48 ; 2$ vs. $4: t=1.31 ; 3$ vs. $4: t=1.12$ ).

\section{Winners' Bids Significantly Decrease After Experiencing the Good}

We can reject the preference learning null hypothesis. Winner bids fell after they experienced the good. ${ }^{8}$ The lower panel of

\footnotetext{
${ }^{7}$ The parametric results are broadly consistent with findings from non-parametric tests. The non-parametric test results are available from the authors on request.

${ }^{8}$ The number of winner bids is determined as follows: there is one winner per session, and we observe each of the winners' bids in subsequent sessions, e.g., winner in session bids fifteen times in
}

table 1 contains summary estimates of winners' behavior in the auctions. A consistent result across each of the three good types is that bids tend to decrease sharply once a person wins and actually consumes the good. Our $t$-tests verify this premise. In each case we reject equality of the mean winners' bids at better than the $p<0.001$ confidence level (candy: $t=-5.06$; mango: $t=$ -8.24 ; pork: $t=-4.53$ ). These results suggest that experience with the goods matters. 'This result implies that winners' behavior needs to be controlled for when examining aggregate subject bidding behavior. To account for these and other factors, we complement the unconditional findings with empirical estimates from an econometric model. This procedure allows us to identify the role that familiarity with the lab, and the good, have on bidding behavior.

\section{Conditional Empirical Methods}

We estimate the following model for the three categories of panel data:

(1) $\operatorname{Bid}_{i t}=\alpha_{i}+\sum_{1}^{3} \beta S_{t}+\sum_{1}^{2} C X_{i t}+\varepsilon_{i t}$

where $\operatorname{Bid}_{i t}$ denotes subject $i$ 's bid in trial $t ; \alpha_{i}$ represents a fixed/random bidder effect, which controls for individual specific timeinvariant effects such as subjects' private values and subjective risk perceptions for the good; $S_{t}$ are dichotomous variables that represent our four data gathering sessionswe exclude session four and therefore the $\beta$ estimates represent deviations from this baseline session; $X_{i t}$ are other factors that may affect bidding behavior. In $X_{i t}$, we include lagged price to control for any posted price effects, ${ }^{10}$ and a dichotomous variable that indicates whether the participant was a winner of the item in a previous session. Define winner $=1$ if the subject previously won an auction, 0 otherwise.

sessions two-four. We are looking at three observations for each good, and potentially thirty more observations in total, $15+10+$ $5=30$. Given that we pooled data across two treatments for each good, there may be as many as sixty "past winner" observations for each of the three goods. In practice the number is smaller due to subjects winning more than once. In our case, the candy, mango, and pork models had 50,40, and 60 winner observations.

${ }^{9}$ One might also argue that our results simply suggest that the winning subjects' demand curves were downward sloping. While this is a possibility, we think it is likely that the two-four day time lag between auctions reduced the probability of diminishing returns and satiation.

${ }^{10}$ See for example List and Shogren. 
Table 2. Fixed-Effects Estimation Results of Bid Function

\begin{tabular}{lccc}
\hline & Candy & Mango & Pork \\
\hline Variable & & & \\
Session 1 & -0.005 & -0.01 & $0.051^{*}$ \\
& $(-1.48)$ & $(-1.45)$ & $(5.54)$ \\
Session 2 & -0.001 & 0.005 & $0.024^{*}$ \\
& $(-0.30)$ & $(0.74)$ & $(2.88)$ \\
Session 3 & 0.003 & 0.011 & 0.011 \\
& $(0.76)$ & $(1.59)$ & $(1.44)$ \\
Winner & $-0.033^{*}$ & $-0.141^{*}$ & $-0.10^{*}$ \\
& $(-5.55)$ & $(-13.19)$ & $-6.72)$ \\
Lagged Price & $0.18^{*}$ & $0.14^{*}$ & $(-1.60)$ \\
& $(3.05)$ & $(4.21)$ & 0.75 \\
$R^{2}$ & 0.57 & 0.66 & 0.73 \\
Adjusted $R^{2}$ & 0.54 & 0.64 & 39.2 \\
$F\left(\alpha_{i}=0\right)$ & $19.1^{*}$ & $32.6^{*}$ & $(29,534)$ \\
$($ d.f. $)$ & $(29,534)$ & $(29,534)$ & 570 \\
$\mathrm{~N}$ & 570 & 570 & \\
\hline
\end{tabular}

Note: $t$-ratios in parentheses beneath coefficient estimates.

* Significant at the $p<0.01$ confidence level.

We obtained econometric estimates of equation (1) for fixed and random effects models of panel data.

Table 2 contains our panel data estimation results. Since fixed and random effects estimates are very similar, we present only the within estimates in table $2 .{ }^{11}$ Statistical tests of the homogeneity of individual effects, $\alpha_{i}=0$, leads us to reject the null hypothesis of identical fixed effects for all models at the 1\% level (candy: $F=19.1$; mango: $F=$ 32.6; pork: $F=39.2$ ), implying that subject invariant factors such as private values are important and need to be controlled in the regression context. Other diagnostic statistics indicate that our relatively parsimonious model performs reasonable well, as adjusted $R^{2}$ values range between 0.54 and $0.73 .^{12}$

\section{Conditional Results Suggest that Bidding Behavior Differs Across Sessions, but Only for Unfamiliar Goods}

Coefficient estimates in the candy and mango regressions serve to reinforce the unconditional estimates in table 1-subjects' bidding behavior does not change dramatically across

\footnotetext{
${ }^{11}$ Random effects estimates are available upon request. Concerning nonzero bids, we found that $25.4 \%, 27.7 \%$, and $58.1 \%$ of the bid observations are nonzero for the candy, mango, and pork data. Note that for the models that converged (mango and pork), a random effects Tobit model provided results that were consistent with findings from the fixed effects estimates presented in table 2 .

${ }^{12}$ We detected neither heteroscedasticity nor serial correlation in the data.
}

the four sessions for these two goods. These results imply that subjects are not enticed to bid differently on familiar goods when they are confronted with a relatively new situation - the lab. Empirical estimates in the pork regression are much different. In the pork auctions, we find that subjects tend to decrease their bids slowly over sessions. For example, a coefficient estimate of 0.051 for the session one dummy variable indicates that controlling for price, whether the subject was a previous winner, and subjectspecific effects, participants bid about a nickel higher in the first session compared to the fourth session. Given that the mean bid in all four sessions was approximately 9 cents, this decrease is quite dramatic.

Coefficient estimates of session two and session three, 0.024 and 0.011 , indicate that the level of subjects' bids declined slowly, rather than rapidly. In session two, a significant coefficient estimate suggests that subjects were still bidding higher than comparable bids in the fourth session. This novelty effect appears to wane, however, as bidding in the third session is not significantly different from bidding in the fourth session. Combining empirical results from the pork regression with estimates from regressions of the familiar goods suggests that people tend to bid in an aggressive manner in early sessions for unfamiliar goods. For familiar goods that the bidder may have had past experience, there appears to be little evidence of a lab novelty effect. 
Conditional Bids From Winners

Significantly Decrease after

Experience With the Good

Estimates of the coefficient of Winner in each auction type imply that winners tend to reduce their bids significantly. Conditioning on subject-specific effects, lagged price, and session number, our estimates imply that winning subjects decrease their bid by about 3.3, 14.1 , and 10 cents in the sessions after they consume the candy, mango, and pork. These results reinforce the unconditional estimates above, which do not contradict the idea that people are trying to learn their preferences for an unfamiliar good. ${ }^{13}$

\section{Concluding Comments}

This paper considers the origins of the high price premia observed in previous lab valuation studies for new food products. We constructed an experimental design in which people bid in consecutive auctions over a two-week period for three goods that differ by familiarity. Our results suggest that preference learning about unfamiliar goods explains the high bids, not the novelty of the lab experience. This subdues the suspicion that novelty of the lab is in itself responsible for artificially high bids. Rather behavior is consistent with the view that a person's bid includes an information value that reflects his desire to learn more about unfamiliar good-i.e., preference learning. Additional research testing the robustness of this result would be welcome. Of particular interest would be research to assess whether our results can be confirmed for contingent valuation exercises - an instrument in which overvaluation seem to be a persistent open question.

\footnotetext{
${ }^{13}$ Note that the coefficient of lagged price is also significant at the $1 \%$ level in the candy and mango models, and suggests that bidders use price information when formulating their bids. But also note that a one dollar change is necessary to induce a bid increase of 18 and 14 cents in the candy and mango models. Since posted prices in the candy (mango) auction were typically less than 10 (20) cents and varied little, this result suggests posted prices are not affecting bids in an economically significant manner.
}

[Received June 1999;

Accepted January 2000.]

\section{References}

Crocker, T., and J.F. Shogren. "Preference Learning and Contingent Valuation Methods" Environmental Policy and the Economy. F. Dietz, F. Van der Ploeg, and J. Van der Straaten, eds. Amsterdam: North-Holland Publishers, 1991, pp. 85-107.

Fox, J., B. Buhr, D. Hayes, J. Shogren, and J. Kliebenstein. "A Comparison of Preferences for Pork Sandwiches Produced from Animals with and without Samatotropin Administration." J. Animal Sci. 73(April 1995):1048-54.

Fox, J., D. Hayes, J. Shogren, and J. Kliebenstein. "Consumer Acceptability of Milk from Cows Treated with Bovine Samatotropin." J. Dairy Sci. 77(March 1994):703-07.

Fox, J., J. Shogren, D. Hayes, and J. Kliebenstein. "CVM-X: Calibrating Contingent Values with Experimental Auction Markets." Amer. J. Agr. Econ. 80(August 1998):455-65.

Grossman, S., R. Kihlstrom, and L. Mirman. "A Bayesian Approach to the Production of Information and Learning by Doing." Rev. Econ. Stud. 46(1977):533-47.

Hayes, D., J. Shogren, S. Shin, and J. Kliebenstein. "Valuing Food Safety in Experimental Auction Markets." Amer. J. Agr. Econ. 77(February 1995):40-53.

Hoffman, E., D. Menkhaus, D. Chakravarti, R. Field, and G. Whipple. "Using Laboratory Experimental Auctions in Marketing Research: A Case Study of New Packaging for Fresh Beef." Mkt. Sci. 12(Summer 1993):318-38.

List, J., and J. Shogren. "Price Signals and Bidding Behavior in Second-Price Auctions with Repeated Trials." Amer. J. Agr. Econ. 81(November 1999)942-49.

Roosen, J., J. Fox, D. Hennessy, and A. Schreiber. "Consumers' Valuation of Insecticide Use Restrictions: An Application to Apples." J. Agr. Res. Econ. 23(December 1998):367-84.

Rutström, E. E. "Home-Grown Values and the Design of Incentive Compatible Auctions." Intern. J. Game Theory 27(1998):427-41.

Vickrey, W. "Counterspeculation, Auctions and Competitive Sealed Tenders." J. Finan. 16(March 1961):8-37.

Viscusi, W.K. Fatal Tradeoffs: Public and Private Responsibilities for Risk. New York: Oxford University Press, 1992. 